\title{
Anthrax of the lower eyelid
}

\author{
Ugur Koçer MD, Hasan Mete Aksoy MD, Yigit Özer Tiftikcioglu MD, Berna Aksoy MD
}

U Koçer, HM Aksoy, YÖ Tiftikcioglu, B Aksoy. Anthrax of the lower eyelid. Can J Plast Surg 2003;11(4):211-212.

\begin{abstract}
Because cutaneous anthrax, caused by Bacillus anthracis, is rare in developed countries, sporadic cases of anthrax may easily be overlooked because the diagnosis is often difficult to make. Lower eyelid involvement of anthrax is rare in clinical practice.

A 40-year-old woman with a history of contact with animals was evaluated and treated for a left lower eyelid lesion with a black eschar on it. A diagnosis of cutaneous anthrax had been made and intravenous penicillin had been given by the department of infectious diseases before plastic surgery consultation. Any kind of surgical intervention was delayed for three months. The lesion healed secondarily and the resulting scar did not result in ectropion of the lower eyelid.

Delaying surgery is preferred because it is a safer approach when dealing with anthrax involving the lower eyelid, and secondary healing does not always result in deformity compromising function.
\end{abstract}

\section{Le charbon de la paupière inférieure}

\begin{abstract}
Comme le charbon cutané, causé par le Bacillus anthracis, est rare dans les pays industrialisés, les cas sporadiques de charbon peuvent facilement être ignorés parce que le diagnostic est souvent difficile à poser. L'atteinte de la paupière inférieure par le charbon est rare en pratique clinique.

Une femme de 40 ans ayant des antécédents de contacts avec des animaux a été évaluée et traitée pour une lésion de la paupière inférieure présentant une escarre noire. Un diagnostic de charbon cutané a été posé, et de la pénicilline intraveineuse a été administrée par le département d'infectiologie avant une consultation en chirurgie plastique. Toute forme d'intervention chirurgicale a été reportée pour une période de trois mois. La lésion a ensuite guéri, et la cicatrice n'a pas entraîné d'ectropion de la paupière inférieure.

Il est préférable de reporter l'opération parce que c'est une démarche plus sûre face au charbon de la paupière inférieure, et la cicatrisation secondaire ne provoque pas toujours de malformation compromettant la fonction de la paupière.
\end{abstract}

Key Words: Anthrax; Delayed surgery; Lower eyelid

A nthrax is an acute necrotizing infection caused by Bacillus anthracis. B anthracis is a large, nonmotile, encapsulated, chain forming, aerobic, Gram-positive rod that forms oval spores. Spores of B anthracis can survive for years in dry earth. All animals are susceptible to varying degrees, but the disease is most prevalent among domestic herbivores (including cattle, sheep, horses and goats) and wild herbivores. Biting flies have also been implicated as vectors for the spread of anthrax. It is difficult to determine the annual worldwide incidence of human anthrax, because many cases do not receive medical attention and are not reported; estimates of 20,000 to 100,000 cases per year have been made (1).

Approximately $95 \%$ of human cases of anthrax are the cutaneous form (1). Because cutaneous anthrax is rare in developed countries, sporadic cases of anthrax may easily be overlooked because diagnosis is often difficult to make. Moreover, lower eyelid involvement of cutaneous anthrax is rarely seen in clinical practice.

A case of lower eyelid anthrax in a 40-year-old woman from a rural area of Turkey is presented.

\section{CASE PRESENTATION}

A 40-year-old married woman who had a history of close contact with animals was evaluated for a lesion with a black necrotic eschar on the left lower eyelid. The lesion started a month earlier as a localized swelling of the periorbital area.
The swelling increased and affected all of the face. The lesion progressed through a pustular stage to the formation of an ulcer with a painless, blackened $3.5 \times 3.0 \mathrm{~cm}$ necrotic eschar surrounded by a zone of edema (Figure 1). Scrapings from the necrotic tissue showed Gram-positive rods, and a culture grew $B$ anthracis. A diagnosis of cutaneous anthrax was made. Intravenous penicillin was started and the patient responded well to the treatment. The edema subsided but the eschar remained. Surgical intervention was delayed for three months after consultation with the department of infectious diseases. The lesion healed secondarily and the resulting scar did not result in ectropion of the lower eyelid, so the patient was not operated upon.

\section{DISCUSSION}

Human cases of anthrax are classified as agricultural or industrial, on the basis of epidemiological settings in which they occur (1). Agricultural cases result most often from contact with animals that have anthrax (for example, during skinning, butchering or dissecting), from bites of contaminated or infected flies, and from the consumption of contaminated meat. Industrial cases are associated with exposure to contaminated hides, goat hair, wool or bones.

Approximately $95 \%$ of human cases of anthrax are the cutaneous form, and about $5 \%$ are the inhalation form (1). Gastrointestinal anthrax is rare and anthrax meningitis occurs 


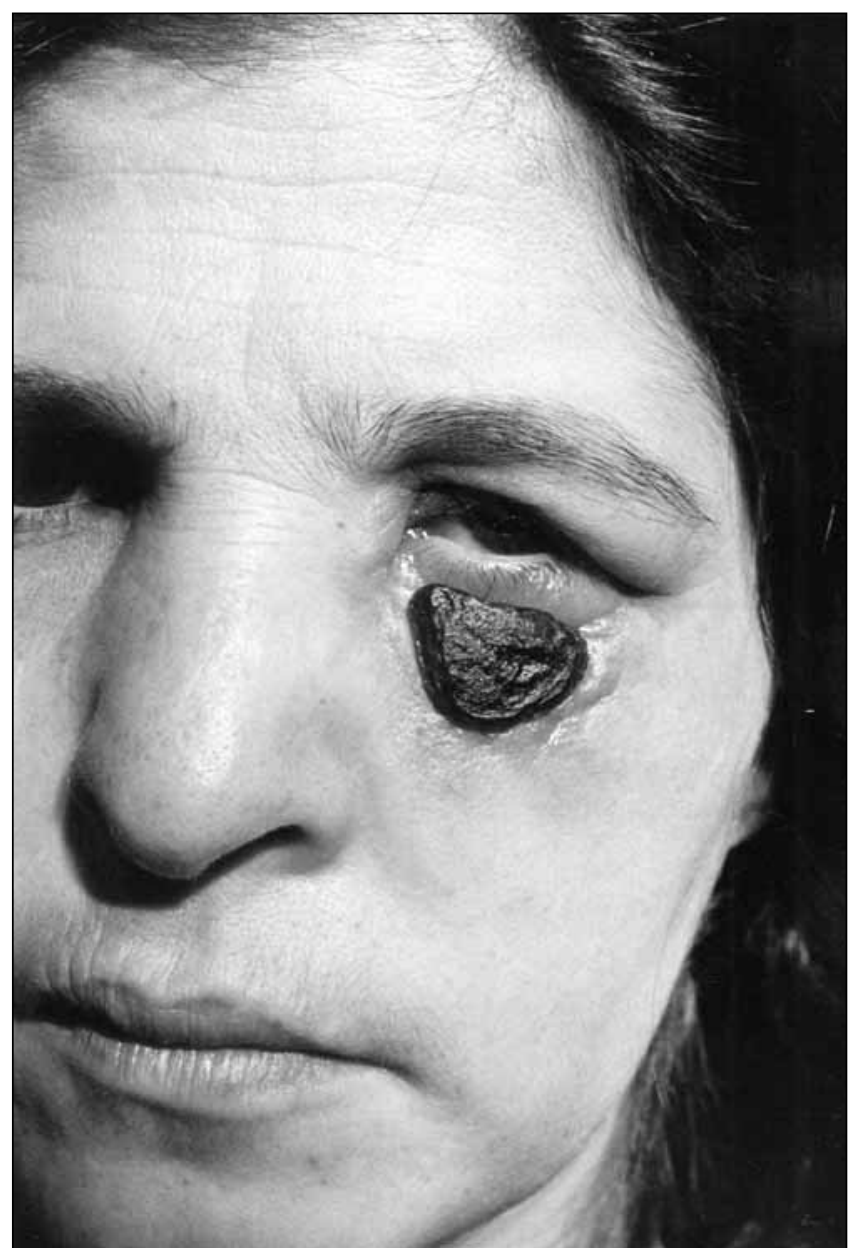

Figure 1) Appearance of the necrotic eschar on the left lower eyelid

in a small percentage of all cases (1). Cutaneous anthrax is initiated when spores of $B$ anthracis are introduced into the skin through cuts or abrasions, or by biting flies. Within days after the inoculation of $B$ anthracis spores into the skin, a small red macule appears. During the next week, the lesion typically progresses through vesicular or pustular stages to the formation of an ulcer with a blackened necrotic eschar, surrounded by a highly characteristic, expanding zone of brawny edema. The early lesions may be pruritic and the fully developed lesion is painless. The cutaneous lesion in anthrax is most often found on exposed areas of skin such as the hands and the face (1). Eyelid involvement may be seen in the cutaneous form of the disease but this is an uncommon occurrence (2).

Because cutaneous anthrax is rare in developed countries, sporadic cases of anthrax may easily be overlooked because the diagnosis is often difficult to make. In addition, lower eyelid involvement of anthrax is rarely seen in clinical practice and should be considered in the differential diagnosis of similar eyelid lesions caused by staphylococcal skin infections and tularemia $(1,3)$.

Cutaneous lesions of anthrax on the eyelids can lead to cicatrization and ectropion (4). Thus, surgical treatment of these lesions is superior to secondary healing. However, a significant number of authors recommend delay of surgical treatment for up to three months (5). They recommend total skin graft for the upper eyelid and pediculed skin flap for the lower eyelid if an eyelid deformity such ectropion develops after secondary healing is complete (5). We also advocate delayed surgery to correct any eyelid deformity, but would prefer to use a full thickness skin graft for reconstruction of lower eyelid deformities. Following adequate debridement of the ulcer and release of the lower eyelid, reconstruction with full thickness skin grafts gives satisfactory results and alleviates the need for flap reconstruction in delayed cases (6). However, because we did not observe any significant eyelid deformity to correct, no surgical procedure was performed in our patient. Instead, the patient was followed closely to detect any deformity that might develop as a result of scar contracture.

\section{CONCLUSIONS}

Delayed surgery to correct possible eyelid deformities should be the preferred method of treatment because it is a safer approach to dealing with cutaneous anthrax of the lower eyelid; skin grafting is recommended for later correction. However, surgery should only be performed when secondary healing results in a significant deformity that compromises lower eyelid function. Secondary healing does not always result in deformities compromising lower eyelid function. Finally, physicians dealing with diseases of the skin must be familiar with this rare and potentially dangerous condition.

\section{REFERENCES}

1. Holmes KR. Diphtheria, other corynebacterial infections, and anthrax. In: Fauci AS, Braunwald E, Isselbacher KJ, et al, eds. Harrison's Principles of Internal Medicine, 14th edn. International Edn, England: McGraw Hill Health Professions Division, 1998.

2. Daboue A, Traore W, Nacro B, Sawadogo A. Suspected palpebral anthrax in children. (Apropos of 3 cases). Bull Soc Pathol Exot 2000;93:20-2.

3. Amraoui A, Tabbara KF, Zaghloul K. Anthrax of the eyelids. Br J Ophthalmol 1992;76:753-4.

4. Bernard NA. Anthrax of the eyelid. Ophthalmic Physiol Opt 1990;10:300-1.

5. Chovet M, Ducam M, Negrel AD, de la Panouse A. Late aspects of palpebral anthrax. Med Trop 1979;39:91-6.

6. Yorston D, Foster A. Cutaneous anthrax leading to corneal scarring from cicatricial ectropion. Br J Ophthalmol 1989;73:809-11. 